\title{
Human-centered Information for Decision-Making Processes of Future Space Designs
}

Jens, Krister; Das, Anooshmita; Kjærgaard, Mikkel Baun; Gregg, Jay Sterling

Published in:

2020 IEEE International Conference on Pervasive Computing and Communications Workshops (PerCom Workshops)

Link to article, DOI:

10.1109/PerComWorkshops48775.2020.9156227

Publication date:

2020

Document Version

Peer reviewed version

Link back to DTU Orbit

Citation (APA):

Jens, K., Das, A., Kjærgaard, M. B., \& Gregg, J. S. (2020). Human-centered Information for Decision-Making Processes of Future Space Designs. In 2020 IEEE International Conference on Pervasive Computing and Communications Workshops (PerCom Workshops) IEEE.

https://doi.org/10.1109/PerComWorkshops48775.2020.9156227

\section{General rights}

Copyright and moral rights for the publications made accessible in the public portal are retained by the authors and/or other copyright owners and it is a condition of accessing publications that users recognise and abide by the legal requirements associated with these rights.

- Users may download and print one copy of any publication from the public portal for the purpose of private study or research.

- You may not further distribute the material or use it for any profit-making activity or commercial gain

- You may freely distribute the URL identifying the publication in the public portal 


\title{
Human-centered Information for Decision-Making Processes of Future Space Designs
}

\author{
Krister Jens*, Anooshmita Das ${ }^{\dagger}$, Mikkel Baun Kjærgaard, and ${ }^{\ddagger}$ Jay Sterling Gregg ${ }^{\S}$ \\ Technical University of Denmark, Copenhagen, Denmark \\ Center for Energy Informatics, University of Southern Denmark, Odense, Denmark \\ Email:* kjens@dtu.dk, adas@mmmi.sdu.dk ${ }^{\ddagger}$ mbkj@mmmi.sdu.dk, jsgr@dtu.dk
}

\begin{abstract}
In this paper, we propose a Space Inventory Management System (SIMS) framework that incorporates digital and analog data types to identify tangible space feature compositions as driving forces for user comfort and space choices. With a combination of real-time data from 3D stereo cameras and manually collected data points using a digitally advanced tool named ARCGIS PRO, the proposed framework get applied on a real case - An extension of a cafeteria area at the HL Lindner College of Business, USA. With the higher aim to synthesize different modern data streams and create a robust platform for extracting space features and their importance on behavioral outcomes, this article demonstrates the more significant opportunity of feeding human-centered information into the decision-making processes of future space designs.
\end{abstract}

Index Terms-Occupant Behavior, space performance management, space utilization, space-use relationships.

\section{INTRODUCTION}

Modern workplaces and learning environments are increasingly enforcing open spaces, as they support desired outcomes for user comfort and are considered to induce a chain of positive side effects such as better work performances, augmentation in quotidian interaction, improved health and wellbeing [1], [2].

However, the main challenge with open and shared spaces lies in the center of dynamic occupant nature, where the equilibrium of space design features vary according to personal needs in performing various occupant actions. This diversity leads to increasing pressure on building managers to meet the diverse occupant needs while creating an efficient space planning of open and shared spaces within buildings [3].

As a result, the disparity between intentions of design and actual space usage lead to high space rejections, high initial investments, and unnecessary operational costs incurred on the Building Management System (BMS) authorities. Therefore, future designs of buildings require the consideration of more holistic approaches to bridge the gap between space provision and space demands in an efficient manner [4].

Today, a complete and holistic platform that continuously integrates user information about daily activities and behaviors with building performances (e.g. of the suitability of space features for activity types) is still missing. The different sensing technology that can detect human parameters are accumulating inside buildings but still limited to mainly descriptive information (e.g., presence, counts, positions) [5].
The future in achieving the best use of space requires entry into a realm that is not so easily quantified: human behavior that is shaped by collective and subjective norms. For this, the adoption of new tools from, e.g., environmental psychology and sociology into space design becomes a viable and promising opportunity [6]. Deeper insights into occupant perception and behavior require additional means of data sources. The technological complexity that a platform has to face in the future is to combine multiple data types and sources and integrate them in a compatible way for a more robust analysis [5]. As such, feeding information from sensor-driven monitoring, manual observations, surveys, self-reports, and interviews would enable meta-analytical approaches to process information on user perception and behaviors concerning a set of influencing design features.

\section{A. Scope and Research Contribution}

In line with the above motivation, a categorization framework gets proposed for the general representation and integration of building data into pertinent pervasive applications. The framework entails 5 categories - 1. Environmental Quality, 2. Socio-Physical Interaction, 3. Architectural Design, 4. Infrastructural Context, and 5. User Behavior. Each category gets broadly classified into sub-categories, see Figure 2. Based on real-time metadata from $3 d$ stereo cameras and qualitative input from manual observations and user feedback, this proposed framework is applied on a real-case to test its feasibility to interpret and comprehend the multi-faceted nature of human behavior. Based on the described research objectives, the contribution of this paper is -

1. Existing literature get reviewed to investigate the role of space design feature compositions as driving forces for user comfort, space utilization, and choices. This investigation led to the proposed categorization framework, which comprises 15 individual design features associated with space utilization, preferences, and -choices. Thus, addressing prominent design features and comprehend the underlying cause and effects of individual space design features.

2. Proposing a Space Inventory Management System (SIMS), which emphasizes the need for promoting human factors combined with different sensing modalities in sustainable building management.

3. Evaluating the proposed framework on a real casescenario, conducted in HL Lindner College of Business in 
Cincinnati, USA. The data is collected by deploying 3D Stereo Vision Cameras and making inferences on the dataset based on the occupancy distribution and space utilization. Our results highlight the fragmentation of use and activities throughout the test-space and indicate clear associations between use and design. These are based on data validation using ArcGIS Pro and visualizations to conclude on the significance of individual space design features and their impact on utilization rates within the monitored area. The remaining paper is structured as: Section 2 explicitly describes the case scenario and the experimental set-up. Section 3 provides categorization of the space design features into 5 categories followed by Section 4 which outlines the space features embedded into the 5 categories, with examples of measurable key performance indicators. Section 5 elucidates the results, followed by Section 6 , which discusses and reflects on the application in respect to future research directions. Finally, Section 7 provides the concluding remarks.

\section{RELATED WORK}

In the following, a brief overview of selected literature within the field of human-oriented building monitoring systems, including their recommendations for future research, gets highlighted in Table 1. Noteworthy, previous attempts to automate the incorporation of user information into building monitoring processes are often limited to their methodological feasibility; overall building functions or entire buildings are often subjects of inquiry, and less attention is given to specific design features. Moreover, the focus of these studies is often on energy-related issues [3]. The technological novelty of this article is, therefore, the incorporation of digital data sources of human behavior into these systems, while developing a better understanding of how to make use of this information in decision making about the design and operation of buildings.

\section{CASE SCENARIO AND EXPERIMENTAL SETUP}

This section describes the case scenario at the HL Linder College of Business, USA. The experimental case scenario takes place at a continuation of a Cafeteria area, which is a multi-purpose space, divided into three zones for study and recreation. The test-space accounts for an area of around 145 $\mathrm{m} 2$, see Figure 1, and get located between the cafeteria and other critical indoor functions such as the atrium and main entrance. Moreover, a window front is visually connecting the space towards important outdoor spaces, such as a centrally located plaza and a park area on campus. Besides, the area may attract spontaneous encounters from all around campus due to the public cafeteria.

\section{A. Dataset Description}

The test-space gets chosen to demonstrate the application of digital sensing modalities in combination with manual observation techniques and qualitative feedback from users. Therefore, 3D stereo cameras have been mounted at the height of 4 meters, capturing data from a bird's view angle, with

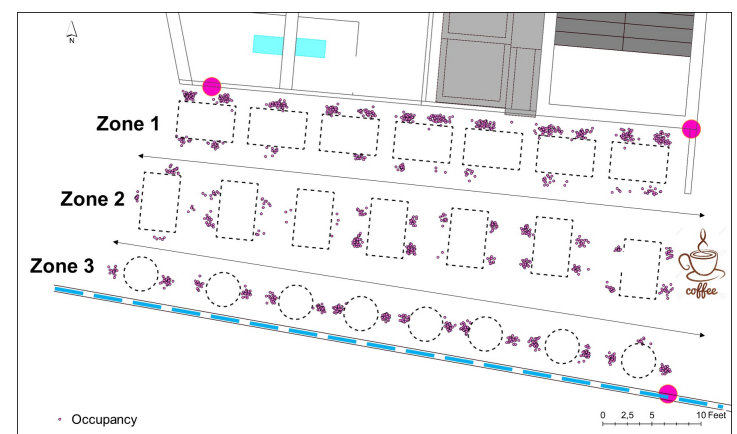

Fig. 1: Case Scenario: The extended Cafeteria space in the College of Business, Cincinnati, USA.

strict compliance with the European Union's General Data Protection Regulation (EU-GDPR).

In the dataset, 1,489,393 readings get extracted from the stereo vision cameras for one week. Each reading contains position coordinates (x-coordinate, $\mathrm{y}$-coordinate), timestamps, and distinct occupant IDs for each person. On average, 119 individual IDs are found in Zone1, followed by 85 in Zone 2, and lastly 71 in Zone 3 during the test period. These readings get validated with manual observations collected with ArcGIS PRO. The dataset attributes are highlighted in Table 2.

\section{B. Sensor Placement}

Camera placement has a significant impact on the overall performance of detecting the activities performed by multiple occupants [11]. The purpose of decent camera placements is to cover the entire monitored space using a minimum number of cameras, and the solution gets determined by the visibility relationship of the cameras and the person beneath performing diverse activities [12].

\section{Categorization of Space Design Features}

For the analysis and decoding of the high dimensional interactions between spatial design features and human occupancy preferences, this paper presents a novel approach of quantifying and integrating information from diverse research areas into a central space performance inventory. With high fidelity movement and occupancy data and the use of efficient observation tools that digitize activity patterns and behavioral variations, the human factor in space design can get increasingly pin-pointed and integrated into informed decisionmaking systems.

The appropriateness of a specific composition of design features varies under their contextual relation to a given use purpose (activity), i.e., not only the perceptional difference of every individual creates a unique spectrum of desired levels of space features. In the existing literature, mostly physical or technical features get focused on when determining the reasons behind human space preferences and comfort levels [13]. With accurate information from modern sensing technologies, there is an opportunity and compatibility to mix various types of data types. The direction of research changes rapidly with the increased availability of user information. 
TABLE I: OVERVIEW OF THE RELATED WORK

\begin{tabular}{|c|c|c|c|c|}
\hline Author and Year & Sensor /Data Used & $\begin{array}{l}\text { Design Features / } \\
\text { Case Study }\end{array}$ & Characteristics & $\begin{array}{l}\text { Future Research } \\
\text { Recommendation }\end{array}$ \\
\hline $\begin{array}{l}\text { Tushar, et al. } \\
\text { (2018) [7] }\end{array}$ & $\begin{array}{l}\text { Thermal imaging, } \\
\text { CV cameras, } \\
\text { sound sensors }\end{array}$ & Meeting rooms & $\begin{array}{l}\text { An unsupervised learning } \\
\text { technique labeled by deep- } \\
\text { learning-based occupancy } \\
\text { detection that uses information } \\
\text { obtained by sound sensors. }\end{array}$ & $\begin{array}{l}\text { There is a need } \\
\text { to extend this work } \\
\text { to present more } \\
\text { quantitative analysis } \\
\text { in terms of performance } \\
\text { compared with existing } \\
\text { studies in the literature } \\
\text { and analyze how head } \\
\text { counting impacts the energy } \\
\text { consumption of the building. }\end{array}$ \\
\hline $\begin{array}{l}\text { Ghahramani, } \\
\text { et al (2016) [8]. }\end{array}$ & $\begin{array}{l}\text { Infrared sensors, } \\
\text { indoor environmental } \\
\text { sensors }\end{array}$ & $\begin{array}{l}\text { Temperature, } \\
\text { humidity, } \\
\text { human comfort } \\
\text { Office }\end{array}$ & $\begin{array}{l}\text { The proposed technique } \\
\text { allows for continuous } \\
\text { monitoring of thermo-regulation } \\
\text { performance, as well as } \\
\text { instantaneous identification of } \\
\text { thermal comfort during } \\
\text { daily office activities }\end{array}$ & $\begin{array}{c}\text { Future research } \\
\text { should involve to } \\
\text { increase occupant } \\
\text { satisfaction by selecting } \\
\text { optimal control } \\
\text { parameters. }\end{array}$ \\
\hline Ang,et al (2016) [9]. & $\begin{array}{l}\text { Z-Wave Aeon } \\
\text { Multi Sensor, } \\
\text { motion sensor, } \\
\text { SmartThings Smart } \\
\text { Power Outlet, } \\
\text { Netatmo Urban } \\
\text { Weather Station }\end{array}$ & $\begin{array}{c}\text { Temperature, humidity, } \\
\text { air quality, } \\
\text { sound level, atmospheric } \\
\text { pressure, } \\
\text { illumination, } \\
\text { whether the door } \\
\text { was open or closed }\end{array}$ & $\begin{array}{l}\text { By using only } \\
\text { non-intrusive ambient sensor } \\
\text { data, we have shown } \\
\text { that it can be used } \\
\text { to recognise indoor } \\
\text { human occupancy accurately. }\end{array}$ & $\begin{array}{c}\text { Future work } \\
\text { includes the isolation } \\
\text { of attributes related } \\
\text { to the estimate of } \\
\text { the number of occupants } \\
\text { in different rooms } \\
\text { with varying } \\
\text { configurations and } \\
\text { usage patterns. }\end{array}$ \\
\hline Cha, et al (2016) [10] & $\begin{array}{l}\text { Noise Sensors, } \\
\text { Lux Sensors }\end{array}$ & $\begin{array}{c}\text { Noise levels, lighting levels, } \\
\text { distances to windows, } \\
\text { furniture types, } \\
\text { degree of enclosure }\end{array}$ & $\begin{array}{l}\text { The resulting model } \\
\text { clearly explains space } \\
\text { preferences for group } \\
\text { work-related activities } \\
\text { and predicts spatial-choice } \\
\text { behavior by generating } \\
\text { space-use probabilities } \\
\text { for given spaces. }\end{array}$ & $\begin{array}{l}\text { Further research } \\
\text { is needed to fill } \\
\text { the gap between } \\
\text { subjective levels and } \\
\text { objective levels } \\
\text { in the space-preference } \\
\text { models, so that the } \\
\text { information from the } \\
\text { models can become } \\
\text { a more robust and } \\
\text { reliable reference. }\end{array}$ \\
\hline
\end{tabular}

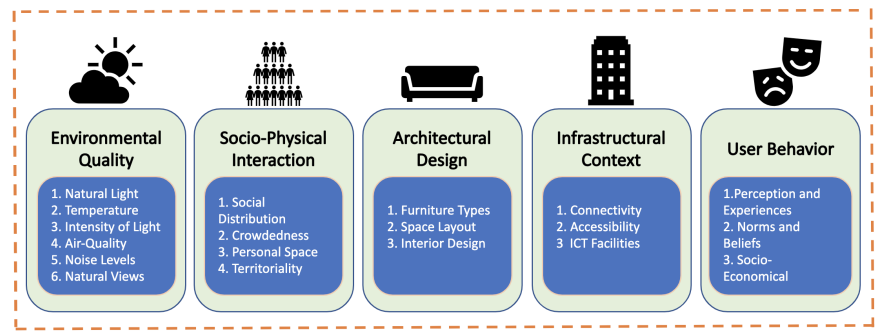

Fig. 2: Categorization of the space design features that impacts space utilization and space choices.

TABLE II: THE ATTRIBUTES INCLUDED IN THE DATASET

\begin{tabular}{ll}
\hline Attributes & Description \\
\hline Time & Time-stamp when the entries were collected. \\
Day ID & $\begin{array}{l}\text { Randomly assigned number which holds the ID for the } \\
\text { specific day in the dataset. }\end{array}$ \\
X Coordinate & Represents the spatial position in X-axis, in decimal. \\
Y Coordinate & Represents the spatial position in Y-axis, in decimal. \\
Occupant ID & Each head-count is assigned a unique Occupant-ID. \\
Height & Occupant height in millimeters. \\
Camera ID & The name of the camera which collected the entries. \\
\hline
\end{tabular}

There is an attempt in this paper to incorporate human behavioral factors with space design features and identify the linkage or association between space use preferences. Also, to try to comprehend the inter-relationships between different space features and how they influence the building spaces and their usability. This research work would enable us to overcome the drawbacks of previous works that mainly focus on physical space features and ignoring the behavioral aspects.

Figure 2 provides an overview of the categorization of space design features. These are based on empirical research about prominent space features on occupant behavior and can persuade the different space selections by multiple occupants [3] [1]. The categorization incorporates measurable features and gets broadly classified into 5 categories - 1. Environmental Quality, 2. Socio-Physical Interaction, 3. Architectural Design, 4. Infrastructural Context, and 5. User Behavior. The explicit 
focus here is to redefine the importance and feasibility of incorporating human features into modern building monitoring.

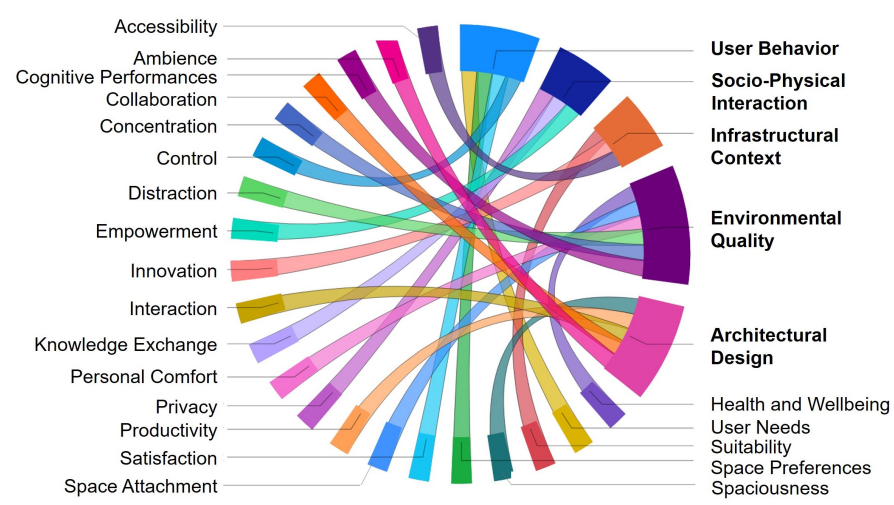

Fig. 3: Examples of potential effects of each space design feature in the categorization framework.

The 5 categories get further highlighted with findings from the literature that indicate the opportunities for a meaningful alignment of spatial and human factors in building design and operation. As seen in Figure 3, the potential of increasingly considering human factors in space design range from monetary benefits such as improved space efficiency and utilization to organizational and human benefits such as health, wellbeing, productivity, empowerment, space attachment, amongst others.

An explicit description of each the sub-categories of the framework gets highlighted below:

\section{A. Environmental Quality}

The environmental features considered in this framework involve compelling features such as lighting- and noise levels, air quality and -temperature, and natural views. Lighting conditions and diverse intensity levels of light can influence the sitting preferences or space-choices made by an occupant and can support or hinder cognitive functioning [1]. The noise factor manifests the acoustic comfort of occupants. Another crucial factor is the visual distances and natural views that can be measured based on the distance to windows, for instance, which may have a positive correlation with more number of users [3].

\section{B. Socio-Physical Interaction}

Socio-physical features are extracted mainly from the fields of environmental psychology, where concepts of territoriality, personal space, crowdedness, and social densities can direct insights about space choices [14]. Territorial behavioral patterns are related to personal space and control, typically including nonviolent signals such as occupation and personalization of a given setting. The concept of personal space defines the distance and orientation of interpersonal relations, closely aligned with the physical setting in which they take place. Personal and contextual influences interact with space choice behaviors and certainly with interpersonal distances. For example, research suggests that social interaction and cooperation generally reduce the interpersonal distance, while less spacious physical settings increase the distances, depending on cultural and individual preferences [14]. Incorporating knowledge of socio-physical concepts into the designs of open spaces may allow users to control the environment as the organizational context allows, which in turn has positive effects on the greater sense of self-determination and identity [1]

\section{Architectural Design}

Architectural design faces towards the abstract strategy and purpose with a structure, involving layout, ratios, and interior design elements. The amount of physical space determines the over- or under-utilization of a space. Existing research suggests that open and spacious environments boost the performance of creative, abstract, and relational thinking among users [1]. The design aspect here specifies its implementation and practice, including interior design aspects such as furniture types and arrangements. A large body of literature endorses the importance of comfortable; adjustable furniture is functional, inspiring spaces [1]. Thus, an adjustable environment with a variety of furniture types and comfort levels and a casual atmosphere contrasted to formal spaces gets affirmed to stimulate the time that workers spend in shared spaces. This factor depends on interior design elements such as space layout and types of furniture. This includes the appropriate arrangements of furniture that support user activities and persuade space selection.

\section{Infrastructural Context}

Open and shared spaces typically depend on support structures to facilitate the diverse range of user activities. Surrounding functions like meeting rooms, offices, classrooms, restrooms, cafeterias, or outdoor areas have shown to impact the use of social spaces. Space preferences are influenced by the perceived effectiveness of self-direction, finding suitable spaces for working alone or together. For work-related activities, students appear to be most concerned about functional aspects of space over aesthetics, for instance. User groups in these studies prefer open, unconfined environments, and other studies indicate the importance of spatial attributes, including visibility and ICT facilities. Certainly, ICT facilities (e.g., PCs, printers, screens, access to software, WIFI) are gaining momentum when it comes to attracting users to shared spaces within buildings. Technical equipment such as plugs and sockets would typically increase space occupancy patterns. Connectivity refers to the locational accessibility and equipment adequacy and relates to the appropriate arrangements of functions that complement each other and support user activities. The ability to rearrange and move the equipment within a space would increase the flexibility required for their activities and improve the suitability and adaptation of design intentions.

\section{E. User Behavior}

Design that addresses the human cognition of individual occupants is gaining momentum in that physical and virtual 


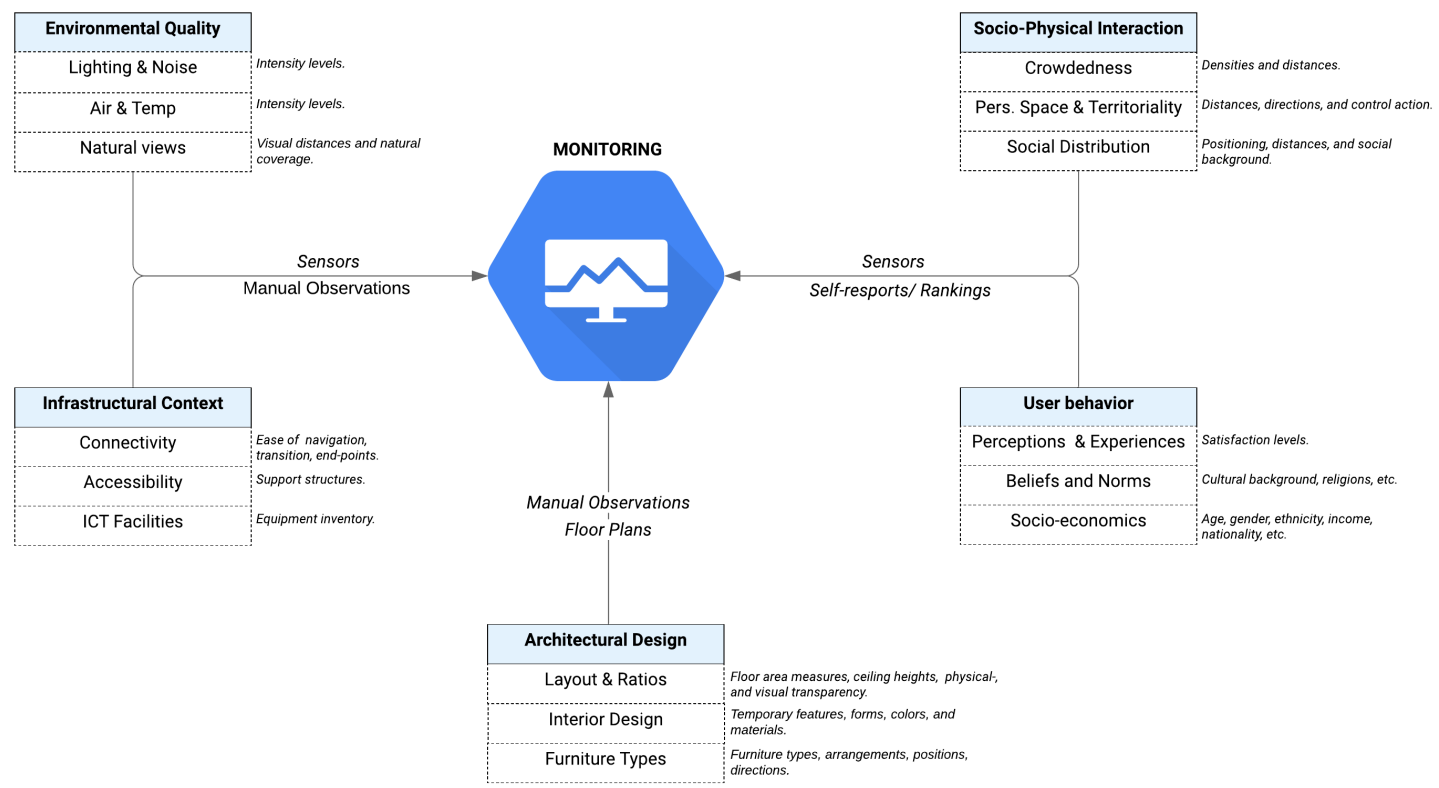

Fig. 4: The Space Inventory Management System (SIMS): Proposed categories and key performance indicators (in italics).

environments define the sensory experience of occupants. User behavior and perceptions are mental processes of transforming sensory stimuli into meaningful information. It is the process of interpreting and judging a situation, and in the proposed framework [13], user behaviors and perceptions get associated with all of the previously outlined subcategories. This is due to the influences on user behaviors based on individual perceptions and experiences with architectural, infrastructural, environmental, and socio-physical factors. Notably, user information such as cultural background, norms and beliefs, education, and social status may play a vital role in space selection and choices made by the user.

\section{Space InVEntory Management Systems (SIMS)}

The proposed framework in this paper, the Space Inventory Management System (SIMS), provides substantial information regarding different space-use relations within the building. The primary purpose of SIMS is to incorporate diverse categories and the embedded design features, extrapolate the association links, and comprehend the reasons behind it. This extrapolation requires careful introspection to extract the interrelationships between the different space design features.

SIMS highlights the association between the five broad categories and the space design features to measurable performance indicators. The categories in the framework have equal weights and comprise 15 design features for comparison. The robustness of SIMS depends on the input data types and the sensing modalities used. For example, natural lighting and noise levels can be obtained from sensors, while visual distances use floor maps to determine green coverage and natural views. Distances, positions, directions of occupants, and sudden (control-) actions indicate aspects of Personal Space, Territoriality, and Social Distribution and can be extracted by cameras with high accuracy. This entails activity types related to the framework categories. SIMS reflect a considerable potential benefit for building managers to optimize space use and user experience; see Figure 4.

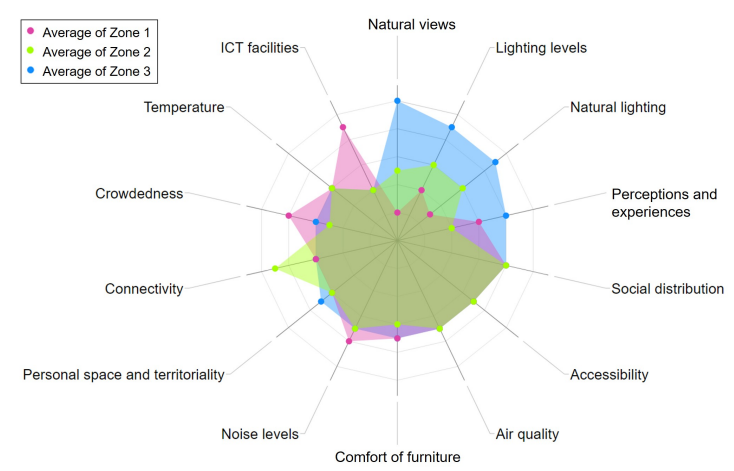

Fig. 5: Radar plot of the spatial representation of design features within the test-space.

This diversity of the three zones gets reflected in Figure 5 , where the design features get labeled according to their level of presence, either in terms of intensities or quantities (1$3=$ low, 4-6=medium, 7-10=high) (Assumptions in terms of air quality and temperature). Accordingly, spatial qualities - in the context of this study refers to the design features present, and 
also referring to the relationship of a feature with space and space users - is identified to illustrate the deviations between the three zones visually.

\section{Results}

This section interprets the results from applying SIMS on the conducted case scenario, where the space design features within the test-space are extracted and briefly evaluated. The visualization plots show results from the data collected in week 41, 2019.

The occupancy distributions within the space are analyzed to identify utilization rates throughout the zones. Utilization rates are measures of how much a given space is used (headcounts) in the available time, expressed as a percentage. Information about the over- or under-utilization of a given space plays a vital role for space managers to assess operating efficiencies and react to changing use trends. As seen in Figure 6, the three zones show different utilization rates on a daily/hourly (A) and weekly/daily (B) basis.

In averaged hourly terms during the day (see Figure 6 (A)), Zone 1 dominates with almost evenly distributed utilization rates (around 50-60\%) with no significant responses to peakhours (from 11 am-1 pm). From this, we can assume that functional aspects like furniture types and the more substantial provision of ICT facilities in that zone determines higher utilization rates for work-related activities. Zone 2 gets used mostly during the morning hours, which can be associated with the schedules of classes and the physical connection to surrounding (support-) functions like the Cafeteria nearby. Here, the space layout may support quotidian interaction during waiting times in the morning and foster recreational activities. Zone 3 has the highest utilization rate at 9 am, reaching around $50 \%$, which then drops significantly and only tends to increase its population from the afternoon onwards. Visual aesthetics, natural light, and smaller tables may influence space utilization patterns for personal and recreational interaction in Zone 3. When it comes to the weekly distribution in Figure 6 (B), it can be deduced that the general utilization of Zone 1 increases significantly towards the weekend from Thursday on, with peak rates of above $70 \%$ on Friday. In Zone 2 and 3, the utilization rates vary between $25-40 \%$, with a steady pattern throughout the week.

Another way to visualize these findings is to use heat maps (see Figure 7), which illustrates the substantial utilization of Zone 1 during the day (A) and its steadily growing utilization towards the weekend (B). Occupancy distribution for the week shows fewer fluctuations in both zone 2 and 3 , while zone 1 shows high space utilization towards the weekend. Zone 3 shows marginalized use patterns in the morning ( $9 \mathrm{am})$ and in the afternoon $(4 \mathrm{pm})$ and is mainly under-utilized in-between. The space utilization of the different zones varies between weekdays. Interestingly to note, that Thursday and Friday show high use rates, which can be influenced by architectural and infrastructural factors that require further investigation.

Besides, occupancy distributions also indicate social densities (counts and distances) between space users, which
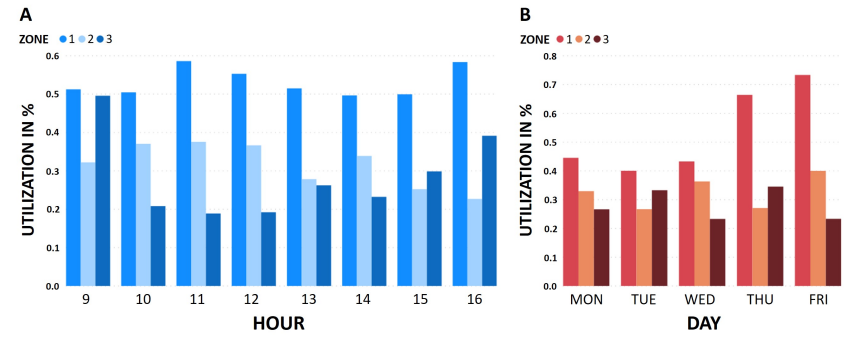

Fig. 6: Occupancy Distribution from Xovis 3 D Stereo Vision Camera A. One Day (Hourly: 9 am - 5 pm) B. One Week
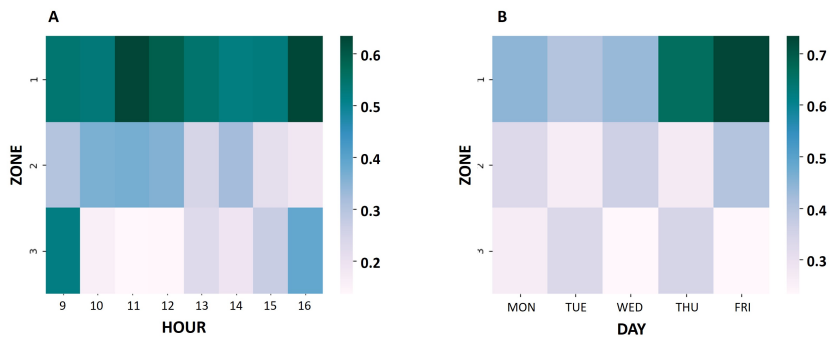

Fig. 7: Zone Utilization from 3D Stereo Vision Cameras A. One Day (Hourly: 9 am - 5 pm) B. One Week.

provides insights into aspects of space preferences, personal space, territoriality, and crowdedness. When combining earlier utilization rates with other information about activity types and population characteristics, underlying factors of utilization rates get investigated; In Zone 3, we find a higher amount of recreational activities in line with great environmental design features such as natural views and natural light. The tendencies towards Zone 1 gets highlighted and may be related to a higher amount of work-related activities in line with higher functional design feature presence such as power plugs (Infrastructural Context) and desk sizes (Architectural Design).

\section{Discussion, APPliCATIONS AND Future RESEARCH DIRECTION}

As markets become competitive, and space planners get challenged for creating more sophisticated space with fewer resources, digital data sources become increasingly important to make informed decisions about space design and operation. Outdated buildings are inefficient in terms of utilization rates, and the impact of modern layouts are not fully understood yet. User expectations are changing, and building organizations are looking for greater flexibility, mobility, and collaboration. Design that addresses occupant behavior can help to tune the design to the intuitive needs of occupants.

Human behavior is key to the design and operation of spaces and reveals the ability to go beyond the physical and technical aspects of building performances. Although, in recent years, the digital sensing application domain is growing, there are still some fundamental problems that relegate a deeper understanding of space-use intentions for different reasons. 
Firstly, the collection of personal data gets challenged by technological issues, the associated costs, and specifically the lack of maturity in technologies in terms of data collection, processing, and visualization. Traditional building monitoring systems primarily focused on the technical and physical aspects without taking the user's requirements into account - a level of complexity that is related to dynamic behaviors, as human action is not always explained by rationality. Architectural design that fails to make building users an integral part of the early design stages results in inefficient and unhealthy spaces. Failed space management is alienating human factors, and driving up risks of adverse outcomes like discomfort, stress, unnecessary operation costs, reduced work performances, absenteeism, among others. Human resources represent one of the highest costs of any organization, and the achievement of appropriate space provisions that support user needs is, therefore, critical to architects in the design phase, and space planners in the operation phase in general.

An attempt in this direction is carried out by this research study to address dynamic human behavior. The primary aim of this paper is, therefore, to create a data platform that is capable of integrating different data streams with flexibility for future adjustments to manage, monitor, and control space features - while improving the user experience through a centralized, interactive data platform.

The application of SIMS revealed that modern sensing modalities could increasingly capture human factors. Also, it provides original documentation of factors relating to territoriality, personal space, and crowdedness. In terms of $\mathrm{Ar}$ chitectural Design category features - space layout and ratios have been captured, with itemized interior design elements including furniture types, their positions, and directions. Regarding Environmental Quality, only information on natural views and lighting conditions are covered, collected through a hand-held lux-meter to make an informed assumption about lighting levels in the different zones. The space features within the 'Infrastructural Context' category are as well covered, and indeed ICT Facilities show significant influences on space choices. Connectivity and accessibility get evaluated in real terms (Digital connectivity, equipment accessibility), which preferably could also include user perceptions on the contextual understanding of connectivity and accessibility for occupants with individual socio-economic and cultural backgrounds.

In future research, indoor spaces may extensively get equipped with sensor modalities that enable a more detailed analysis in real-time. The measurability of user behavior is still limited to external expressions of occupants, which signifies further research to integrate information on user behavior and direct feedback from occupants to support the results to improve user experiences within modern workplaces and learning environments.

\section{CONCLUSION}

In this paper, the application of a proposed Space Inventory Management System (SIMS) is demonstrated in a real-case scenario, mixing digital and analog data to illustrate the feasibility of increasingly incorporating human factors into modern space monitoring systems. SIMS revealed that modern sensing modalities could increasingly capture human factors. Human behavior is key to the design and operation of spaces, which creates the opportunity to go beyond the physical and technical aspects of building performances when designing and managing building spaces. Design that addresses occupant behavior helps to address the intuitive needs of occupants directly. The integration of new information about dynamic occupant behavior into modern monitoring systems promises to enter new opportunities for researchers, architects, and space managers to comprehend the space-use relationships of modern built environments in the future.

\section{REFERENCES}

[1] K. E. Kariippanon, D. P. Cliff, S. L. Lancaster, A. D. Okely, and A.-M. Parrish, "Perceived interplay between flexible learning spaces and teaching, learning and student wellbeing," Learning Environments Research, vol. 21, no. 3, pp. 301-320, 2018.

[2] A. Das, F. C. Sangogboye, E. S. K. Raun, and M. B. Kjærgaard, "Heterosense: An occupancy sensing framework for multi-class classification for activity recognition and trajectory detection," in SocialSense'19. ACM, 2019, pp. 12-17.

[3] S. H. Cha and T. W. Kim, "The role of space attributes in spacechoice behaviour and satisfaction in an academic library," Journal of Librarianship and Information Science, p. 0961000618794257, 2018.

[4] R. L. Morrison and K. A. Macky, "The demands and resources arising from shared office spaces," Applied Ergonomics, vol. 60, pp. 103-115, 2017.

[5] W. Karwowski and T. Z. Ahram, Intelligent Human Systems Integration 2019: Proceedings of the 2nd International Conference on Intelligent Human Systems Integration (IHSI 2019): Integrating People and Intelligent Systems, February 7-10, 2019, San Diego, California, USA. Springer, 2019, vol. 903

[6] B. Mick, "Factors to designing workspaces for people's behaviors," Work Design Magazine. Saatavissa: https://workdesign. com/2012/06/4factors-to-designing-workspaces-for-peoples-behaviors/[Viitattu: 27.12. 2016], 4.

[7] W. Tushar, N. Wijerathne, W.-T. Li, C. Yuen, H. V. Poor, T. K. Saha, and K. L. Wood, "Internet of things for green building management: Disruptive innovations through low-cost sensor technology and artificial intelligence," IEEE Signal Processing Magazine, vol. 35, no. 5, pp. 100 $110,2018$.

[8] A. Ghahramani, G. Castro, B. Becerik-Gerber, and X. Yu, "Infrared thermography of human face for monitoring thermoregulation performance and estimating personal thermal comfort," Building and Environment, vol. 109, pp. 1-11, 2016.

[9] I. B. A. Ang, F. D. Salim, and M. Hamilton, "Human occupancy recognition with multivariate ambient sensors," in Percom'16 pages $=1$ 6, year $=2016$, organization $=$ IEEE

[10] S. H. Cha, K. Steemers, and T. W. Kim, "Modelling building users' space preferences for group work: a discrete-choice experiment," Architectural Science Review, vol. 60, no. 6, pp. 460-471, 2017.

[11] A. Das, F. C. Sangogboye, and M. B. Kjærgaard, "Mapping the important sensor limitations to design robust occupant sensing systems," in UbiComp'18. ACM, 2018, pp. 1156-1161.

[12] A. Das, E. S. K. Raun, and M. B. Kjærgaard, "Cam-stitch: Trajectory cavity stitching method for stereo vision cameras in a public building,' in AIChallengeIoT'19. ACM, 2019, pp. 8-14.

[13] G. M. Huebner and A. Mahdavi, "A structured open data collection on occupant behaviour in buildings," Scientific data, vol. 6, no. 1, pp. 1-4, 2019.

[14] L. Scannell, M. Hodgson, J. García Moreno Villarreal, and R. Gifford, "The role of acoustics in the perceived suitability of, and well-being in, informal learning spaces," Environment and Behavior, vol. 48, no. 6, pp. 769-795, 2016. 